Chapter 3

\title{
Main Types of Clinical Appearance of Thrombophilic States During Pregnancy - Target Groups for Thrombophilia Testing
}

\author{
Ricardo Barini, Joyce Annichino-Bizzache, \\ Egle Couto, Marcelo Luis Nomura, \\ Adriana Goes Soligo and Isabela Nelly Machado
}

Additional information is available at the end of the chapter

http://dx.doi.org/10.5772/56819

\section{Introduction}

Normal pregnancy is associated with complex changes of hemostasis, leading to hypercoagulability states. Such physiological increase of blood coagulation during pregnancy occurs because of changes in the vascular endothelium and blood flow, generating changes from the 10th gestational week on. The changes may create a hypercoagulability state that results in thrombosis. The purpose of the hypercoagulability state during pregnancy is to prevent excessive bleeding by the time of delivery (Moreira, et al. 2008).

Normal hemostasis during pregnancy is the result of a balance between the system that promotes blood coagulation and the one inhibiting excessive coagulation (fibrinolytic system).

Gestational effects on coagulation proteins may be detected after the 3rd month of pregnancy, with significant changes in pro-coagulant proteins in comparison with physiological inhibitors. So, although changes in hemostatic system are intended for adaptation and protection of the pregnant woman's body, they may cause increased risk of thromboembolic events.

Despite of being physiological, excessive activation of the coagulation mechanism during pregnancy may lead to thromboembolic events, especially in women with hereditary and/or acquired factors who have a known predisposition to thrombi formation.

Thrombophilia is a hereditary or acquired disease related to changes in hemostasis mechanisms that are characterized by an increased trend to blood coagulation and 
consequent risk of thromboembolism (Machac S 2006). Hereditary factors that are considered potentially responsible for such trend to thrombosis are: protein $\mathrm{C}$ deficiency, protein $\mathrm{S}$ deficiency, anti-thrombin deficiency, presence of Factor V Leiden, a change in allele prothrombin $20210 \mathrm{G}>\mathrm{A}$ gene and a change in the gene of enzyme methylenetetrahydrofolate reductase ( $\mathrm{D}^{\prime}$ Amico 2006).

Thrombophilia hereditary causes have been researched since 1956, when Jordan and Nandorff introduced the term thrombophilia. In 1965 anti-thrombin deficiency was identified as the genetic cause of thrombophilia.

Such studies became larger in the 80 's, when protein $S$ and protein $C$ deficiencies were described, as well as Factor V Leiden, in 1994. (Reistma PH 2007). Approximately 40\% of thrombosis cases showing arterial occlusion or venous occlusion are hereditary. Venous thromboembolism frequently occurs as a result of several factors. Generally, thrombophilia should be seen as a multi-factorial disorder, not as the expression of a single genetic change (Buchholz T 2003).

The importance of angiogenesis for embryo implantation and the presence of thrombophilia leading to micro-thrombosis at the implantation site with subsequent impairment of embryo nidation and placental development should be considered as well (Vaquero E 2005).

The presence of thrombophilia was proven to be related to an increased risk of complications during pregnancy, such as pre-eclampsia, intrauterine growth restriction, premature detachment of placenta, preterm delivery, recurrent miscarriage, chronic fetal distress, besides ischemic events during pregnancy (Couto E 2005) (Ren A 2006) (Hoffman E 2012) (Bennet SA 2012).

Events related to thrombophilic changes during pregnancy are shown below.

\section{Thrombophilia and pregnancy}

One of the most important discussions in clinical practice regards the indication to search for a thrombophilic factor. This is due to elevated testing costs and its relevance to medical management once diagnose is done.

Access to Internet and available information on practically all matters brings up questioning by patients who look for these data regarding their personal risks and ask doctors how would they have to behave. It is an important role for doctors to help patients to discriminate which information are relevant for them, helping patient to pursue adequate options for personal treatment and prophylaxis.

There has been a great deal of research relating thrombophilia to many clinical situations where no scientific data is relevant. On the other side, there are still other clinical situations where there is no consensus, or even there will not be a practical condition to define a medical practice, based on studies performed up until now. 
Women are exposed to a great variety of factors that increase their risk of venous thromboembolism (VTE) such as the use of hormonal contraception, pregnancy, puerperium and hormonal replacement therapy for menopause.

The incidence of VTE is higher in woman during pregnancy and post partum when compared to not pregnant women. There is an increase between five to ten times the risks of VTE, with an incidence of 0.6 to 1.3 events for 1.000 deliveries (Heit JA 2005) (McColl MD 1997).

Although there are controversies whether the occurrence of VTE is greater during pregnancy or post partum, it seems that this risk is equally distributed during all gestational period (Pomp ER 2008). VTE is the most important cause of maternal death (Marik PE 2008).

Hereditary thrombophilia include Factor V Leiden (FVL), G20210A prothrombin gene mutation, protein $\mathrm{S}$, protein $\mathrm{C}$ and antithrombin III deficiency.

Prevalence of a hereditary thrombophilia is higher in women that had VTE during pregnancy, especially FVL and G20210A gene mutation. In Japanese populations, protein S seems to be the most common among pregnant women with VTE (Miyata T 2009).

Normal gestation is characterized by hypercoagulation, with increase of coagulation factors II, VII, IX, X, XII, fibrinogen and Von Willebrand factor. There is a reduction in natural anti coagulant factors, such as protein $S$, protein $C$ and antithrombin III. There is also a reduction in fibrinolysis caused by reduction in tissue plasminogen activating factor (t-PA) and increase in the inhibitor of plasminogen activator (PAI-1). Increase of Factor VIII and reduction of protein $\mathrm{S}$ lead to a resistance to activated protein $\mathrm{C}$. Thus, all these changes in pregnancy favor VTE.

After a VTE antecedent, thrombophilia is the most important individual risk factor for a new thrombotic episode during gestation.

Besides VTE, recurrent abortions and other complications during pregnancy can be associated to thrombophilia, particularly protein $S$ deficiency and late complications.

A recent meta analysis has shown that a pregnant woman with thrombophilia has a greater risk than non pregnant woman, particularly in the presence of homozygosis to Leiden Factor $\mathrm{V}$, to G20210A prothrombin gene mutation, in the presence of double heterozygosis for these two mutations and in the presence of antithrombin III deficiency. All of these thrombophilias, except MTHRF 677C >T gene mutation, even in homozygosis, bring about a statistically higher risk of VTE during pregnancy (Robertson L 2006).

The predictive value for the risk of VTE relating pregnancy and thrombophilia is described on table 1. (L. B. Pierangeli SS 2011).

Although, the absolut risk of VTE is low due to the low incidence of VTE itself. Even the risk of VTE in more severe thrombophilia, such as antithrombin III deficiency and protein $S$ deficiency is low. 


\begin{tabular}{ll}
\hline Thrombophilia & PPV* \\
\hline FVL heterozygous state & $1: 500$ \\
\hline prothrombin 20210 G>A heterozygous state & $1: 200$ \\
\hline Double heterozygous state FVL + G20210A & $4.6: 100$ \\
\hline Protein C deficiency & $1: 113$ \\
\hline Antithrombin III deficiency & $1: 2.8$ \\
\hline *PPV- positive predictive values & \\
\hline
\end{tabular}

Table 1. Predictive values of hereditary thrombophilias and VTE.

Medical management of pregnant women with thrombophilia will depend on the risk analysis; which may be complicated, because medical actions are based upon retrospective studies, meta-analysis or case control studies.

The evaluation of other risk factors for VTE, personal and familial VTE history (first degree relatives with VTE or arterial disease at age under fifty years old) should be taken into account seriously.

Hereditary thrombophilia can be classified in thee risk categories (Fogerty AE 2009):

- High risk: FVL homozygosis, prothrombin 20210 G>A gene mutation in homozygosis, double heterozygosis of FVL and prothrombin 20210 G>A, antithrombin III deficiency or any thrombophilia with a previous VTE.

- Intermediate risk: thrombophilia not classified as high risk with family history of VTE.

- Low risk: heterozygosis for FVL, for prothrombin $20210 \mathrm{G}>\mathrm{A}$, protein $\mathrm{C}$ and protein $\mathrm{S}$ deficiency, lack of familial history or personal history for VTE.

As it is observed, personal or familial history of VTE has a strong weight on the VTE risk implication.

A pregnant woman with thrombophilia that presents with VTE during pregnancy has to be treated as a woman without thrombophilia with VTE. Treatment is based on heparin, particularly low molecular weight heparin, with doses adjusted by maternal weight. Warfarin can be exceptionally considered after the first trimester up till 34 weeks gestation. Fondaparinux has already been used in pregnant patients who were unable to use other heparin.

Anticoagulation is recommended for six weeks after delivery for all women with hereditary thrombophilia. During gestation, individual risk should be considered. Patients with high risk should receive heparin prophylaxis as a treatment doses or intermediate dose. Patients with intermediate risk should receive prophylactic heparin dose. Low risk patients should be followed up carefully with strict recommendations to look for medical assistance in the event of any symptoms that can be related to VTE.

Thrombophilia should be searched in any patient with familial history or personal history of VTE or with the diagnosis of a hereditary thrombophilia on a first degree relative. 
A prospective study with 134 pregnant women heterozygous for FVL failed to show an increase in the incidence of VTE. Thus, although being the most common hereditary thrombophilia, its search is not to be indicated indiscriminately on every pregnant patient, nor prophylaxis is to be offered to asymptomatic carriers (Dizon-Townson D 2005).

A recently published meta-analysis including ten prospective studies showed only a small absolute risk for fetal death with demonstration of a small absolut risk with a smaller risk of fetal death on heterozygous FVL (Rodger MA 2010).

It is suggested based on the experience of many studies that generalized search for thrombophilia it is not indicated during pregnancy, except for patients with recent VTE event, or punctual search of a familial or personal in one family member. History of VTE is the most indicated event to look for thrombophilia.

Although thrombophilia are associated to an increase to the relative risk of complications during pregnancy, including VTE, the absolut risk is still low.

\section{Clinical interferences of thrombophilia in pregnancy}

Pregnancy by itself is considered a hypercoagulation state. Likewise for diabetes, it is expected to increase venous or arterial thromboembolism during pregnancy. The increase in estrogen levels leads to increase in many of the coagulation factors. Thus, in the presence of a hereditary or acquired thrombophilia a higher incidence of thrombotic events could be expected. Once a thrombophilic state is already identified, than we can expect a higher chance of clinical and obstetrical complications, except if prophylactic or therapeutic treatments are offered by caring physicians and followed by patients.

Although this is a disseminated belief, systematic reviews fail to demonstrate such strong relation. As stated above, only patients with a familial history of thrombosis or thrombophilia should be investigated.

However, this is not universally agreed on the literature. For instance, a group of patients with Leiden Factor $\mathrm{V}$ were compared to a group of absent mutation. It was observed that the group with the mutation had no thromboembolic events, whereas the group without had 2,7\% thromboembolism (Dizon-Townson D 2005).

It has been also stated that even in relatives of probands who have no history of venous thromboembolism (VTE) should not receive antithrombotic prophylaxis during pregnancy because no difference was seen in the group with and without positive history of VTE prior to pregnancy (Cordoba I 2012). With theses considerations, one must look for evidences presented to date.

\subsection{Thrombophilia and venous thromboembolism}

Pregnancy is a clinical situation associated with increased risk of VTE, which increased from twofold to fourfold when these women presented a positive family history of VTE (Bezemer 
ID 2009). Hereditary thrombophilia also increases the risk of VTE. However, the most important for prevention of thrombosis in pregnant women with these additive risk factors is the negative or positive history of previous VTE.

A meta-analysis and a review demonstrated increased risk of VTE in pregnant women with thrombophilia without a family or a positive history of VTE (Robertson L 2006) (BironAndreani C 2006). Heterozygosis for factor V Leiden and prothrombin $20210 \mathrm{G}>\mathrm{A}$ variant were fortunately associated with the lower risk, as they were the most common inherited thrombophilia. However, the homozygosis for these mutations was associated with the higher risk. Deficiencies of natural anticoagulants were also associated to increased risk of VTE.

The incidence of VTE in the pregnancy is 1/1,000 deliveries, and the absolute risk of VTE in thrombophilic women without a prior event or family history is in the range of 5-12/1,000 deliveries, except for homozygous carriers of the factor $\mathrm{V}$ Leiden or the prothrombin mutations, in whom the estimated baseline risk is about $4 \%$.

Although the estimated risk of VTE in the presence of a positive family history of VTE and inherited thrombophilia without a previous episode of VTE has been described, it is imprecise, particularly for the rare thrombophilias (Friederich PW 1996).

Previous studies described higher risk of VTE in the presence of deficiencies of the anticoagulants, particularly antithrombin deficiency. However, methodological limitations could have contributed to these conclusions (Conard J 1990). The recent studies showed similar risks, even in double heterozygous for Leiden FV and prothrombin mutation (Tormene D 2001) (Martinelli I 2008). The homozygosis for MTHFR C $>\mathrm{T}$ alone does not lead to an increased risk of VTE in pregnant women (Robertson L 2006).

Women with thrombophilia without a family history presented a low risk of VTE. Because of the absence of high-quality evidence measuring the effectiveness and safety of antithrombotic agents in preventing VTE in patients with thrombophilia and a positive family history the recommendations have limitations.

The most recent guidelines suggest antepartum prophylaxis with prophylactic or intermediate-dose LMWH and postpartum prophylaxis for 6 weeks with prophylactic or intermediatedose LMWH or vitamin K antagonists targeted at INR 2.0 to 3.0 for pregnant women with no prior history of VTE who are known to be homozygous for factor V Leiden or the prothrombin 20210 G>A mutation and have a positive family history for VTE (Bates SM and Physicians. 2012).

For patients with other thrombophilias without a previous history of VTE and who have a positive family history for VTE it is indicated antepartum clinical vigilance and postpartum prophylaxis for 6 weeks with prophylactic or intermediate dose LMWH or, in women who are not protein $\mathrm{C}$ or S deficient, vitamin $\mathrm{K}$ antagonists targeted at INR 2.0 to 3.0 (Bates SM and Physicians. 2012).

The same is indicated for pregnant women with no prior history of VTE who are known to be homozygous for factor V Leiden or the prothrombin $20210 \mathrm{G}>\mathrm{A}$ mutation and who do not have a positive family history for VTE (Bates SM and Physicians. 2012). 
Pregnant women with all other thrombophilias and no prior VTE who do not have a positive family history for VTE, antepartum and postpartum clinical vigilance are indicated (Bates SM and Physicians. 2012).

\subsection{Thrombophilia and arterial vascular accidents in pregnancy}

Stroke in pregnancy is one of the main causes of maternal death and pregnancy and puerperium are known to increase its occurrence. The incidence of stroke is not precisely known and there is a wide variation among reports across the world, ranging from 1.5 to 69 per 100 thousand pregnancies (Jaigobin C 2000) (Scott CA 2012). Stroke accounts for $2.2 \%$ of all deaths in women of reproductive age and most of these deaths occur during pregnancy (WHO, 2004). Puerperium increases the risk of stroke 5-18-fold and cerebral thromboembolism carries a mortality rate 3 times higher in pregnant women. Despite the epidemiological association, stroke is considered a multifactorial disease, and genetic, environmental, vascular and hormonal factors play a complex and integrated role. Multiple genes have been studied, and even in the same individual, more than one polymorphism, acting in inflammatory, vascular and thrombotic pathways can lead to stroke.

With increasing worldwide efforts and acknowledgement to know about the causes and lessen the consequences of stroke, pregnant women seem to be a special population, not only because of the greater mortality but also because of the perinatal implications.

Obstetrical associated conditions are chronic hypertension, preeclampsia and cesarean delivery. However, most cases do not have predisposing factors and occur in apparently healthy subjects. Some physiologic changes during pregnancy and puerperium can be associated with an increased risk of stroke: increased circulating blood volume, increased cardiac output, vascular wall fragility, and high levels of steroid hormones.

Preeclampsia seems to be a risk factor even for non-pregnancy associated ischemic stroke, which means that women who had preeclampsia have an increased risk of, is when nonpregnant (Brown DW 2006). Non-obstetric risk factors include thrombophilia (inherited and acquired) migraine, smoking, advanced maternal age, diabetes, sickle cell disease, autoimmune conditions, and severe hypotension (Scott CA 2012).

Stroke in pregnancy and puerperium has three major clinical syndromes: ischemic stroke (IS), intracranial hemorrhage (ICH) and cerebral venous thrombosis (CVT). It is the most frequent presentation and CVT is rare. Maternal mortality can be as high as $50 \%$ for ICH and $20-25 \%$ overall (Nomura ML 2012) (Scott CA 2012).

There are few studies addressing the role of thrombophilia in stroke occurring during pregnancy or puerperium. We will focus mainly in thrombotic and ischemic stroke, since hemorrhagic stroke has different pathogenic mechanisms in pregnancy, mainly related to rupture of undiagnosed intracranial aneurysms and complications of eclampsia. 


\subsubsection{Inherited thrombophilia}

Inherited thrombophilias can be found in up to $11 \%$ of patients with stroke (Bushnell CD 2000). In this systematic review, no association was found between factor V Leiden and IS, but a slight increase in the odds ratio for prothrombin gene mutation was found $(1.4 ; 95 \% \mathrm{CI}$ 1.03-1.9).

A study by Voetsch (Voetsch B 2000) among 167 patients with ischemic stroke and did not find an association with inherited thrombophilia, except in cerebral venous thrombosis, where prothrombin gene mutation was more prevalent. For the small group of patients of African origin, homozygosis for MTHFR 677C $>$ T might have a potential role. Interestingly, patients with CVT were all in use of oral contraceptives or in the puerperium.

Hankey (Hankey GJ 2001) tested 219 patients with ischemic stroke for inherited thrombophilia in a case-control study and did not find a significant association (prevalence of $14.7 \%$ in stroke patients and $11.7 \%$ in control subjects) between any thrombophilia or combination of thrombophilias and IS, and the authors conclude that routine testing is not recommended in the majority of patients.

Kim \& Becker (Kim RJ 2003) performed a meta-analysis of the association between some inherited thrombophilias and ischemic stroke and factor $\mathrm{V}$, prothrombin, and homocysteine metabolism were found to modestly increase the risk in young women.

Weber \& Busch (Weber R 2005) performed a cost analysis of screening for inherited thrombophilias in patients with IS of unknown cause and concluded that screening was of questionable value, with the exception of antiphospholipid antibodies in younger patients.

Corod-Artal et al (Carod-Artal FJ 2005) screened 130 young patients with stroke, and only protein $\mathrm{S}$ deficiency was found to be associated with stroke of unknown cause in young subjects, but in this subpopulation $31 \%$ were oral contraceptive users.

Hamzi et al (Hamzi K 2011) performed the largest meta-analysis to date regarding possible genes associated with ischemic stroke, with more than 150 thousand subjects included. They found that MTHFR 677C >T, factor V Leiden, $20210 \mathrm{G}>\mathrm{A}$ prothrombin and ACE I/D polymorphism had significant, although very modest, associations with IS. However, the authors did not specify results in selected populations, such as pregnant women.

Haeusler et al (Haeusler KG 2012) reported an increased prevalence of factor VII polymorphisms and factor V Leiden (although not significant) in patients with cryptogenic (unknown cause) stroke.

All studies reported might have biases, such as selection of high-risk patients, and there is a lack of controlled, prospective studies in pregnant women. Recommendations for routine screening of inherited thrombophilias in the setting of stroke in pregnant or postpartum women cannot be made at present, since pregnancy itself might be the most important risk factor.

Inherited thrombophilia might play a role when associated with other conditions, acting synergistically or increasing the odds of other risk factors, such as puerperium (particularly 
in CVT), preeclampsia/eclampsia, oral contraceptive use and acquired thrombophilias, such as sickle cell disease.

\subsubsection{Acquired thrombophilia}

Acquired thrombophilia is a condition known to be associated with stroke. Transient cerebral ischemia and stroke (including CVT) are clinical manifestations of antiphospholipid syndrome (APS), but in order to establish the diagnosis a laboratory criteria must also be present, which might be detection in the plasma of lupus anticoagulant, or anticardiolipin antibodies (IgG or $\operatorname{IgM}$ ) or anti-beta2-glycoprotein (IgG or $\operatorname{IgM})$, in at least two occasions, 12 weeks apart, and according to specific standard laboratory guidelines (Miyakis S 2006). The association between IS and APS (primary and lupus-associated) is well established in case-control studies, and even in unselected populations this association seems strong (Bushnell CD 2000).

Patients with previous cerebrovascular events who met criteria for APS should have antithrombosis prophylaxis prescribed when pregnant, with non-fractioned or low-molecular weight heparin. Prophylaxis should be extended into 6 weeks postpartum also. Aspirin can also be added, particularly in the acute phase of an IS.

Patients with APS and previous cerebrovascular events have an increased recurrence risk of IS, and preeclampsia seems to be an additional risk factor (Fischer-Betz R 2012).

Other acquired thrombophilias or thrombophilic status can potentially increase the risk of stroke in pregnancy and puerperium, including sickle cell disease, nephrotic syndrome, dehydration or severe hypovolemic status, and careful attention must be paid in this situations.

\section{Thrombophilia and pregnancy complications}

Adverse pregnancy outcome are not infrequent in general population. Pregnancy complications include miscarriage, fetal loss, preeclampsia, fetal growth restriction, and placental abruption.

The association between inherited thrombophilic disorders and miscarriage, late fetal loss or severe preeclampsia has been described in various studies (Robertson L 2006) (v. d. Coppens M 2006) (Rodger MA 2010).

However, there is a high uncertainty about these associations, particularly for the less prevalent thrombophilia (Robertson L 2006). A meta-analysis including only prospective cohort studies showed only association between factor V Leiden and pregnancy loss, but not with other thrombophilias (Rodger MA 2010).

One randomized trial described increased live birth rate in women with factor V Leiden, the prothrombin gene mutation, or protein $S$ deficiency using enoxaparin when compared with low-dose aspirin alone (Gris et al s et al), but the methodology was limited.

The results of other studies do not provide evidence that LMWH improves pregnancy outcome in women with inherited thrombophilia and recurrent pregnancy loss (F. N. Coppens M 2007). 
Based on these findings the guidelines do not recommend screening for inherited thrombophilia for women with a history of pregnancy complications. There is no indication of antithrombotic prophylaxis for women with inherited thrombophilia and a history of pregnancy complications.

The results of two studies that address this issue, Heparin for Pregnant Women with Thrombophilia [NCT01019655] and TIPPS: Thrombophilia in Pregnancy Prophylaxis Study [NCT00967382] are awaited with interest.

\subsection{Thrombophilia and recurrent pregnancy loss}

Pregnancy loss in humans occurs in up to $75 \%$ of fertilized ova and $15 \%$ of well-confirmed pregnancies (Boklage 1990) and recurrent pregnancy losses (RPL) affect $2-5 \%$ of women in reproductive age (Hatasaka 1994). RPL is usually defined as the loss of three or more consecutive pregnancies before 20 weeks of gestation or with fetal weights less than 500 grams. Within this definition is a large and heterogeneous group of patients with many different causes of miscarriage. RPL frequency increases up to $5 \%$ when clinicians define RPL as two or more losses of pregnancy (Hogge 2003). In addition, epidemiological investigations have demonstrated that the frequency of subsequent pregnancy loss is $24 \%$ after two pregnancy losses, $30 \%$ after three and $40 \%$ after four successive pregnancy losses (Regan 1989). Additionally, recurrent risk for RPL may increase up to 50 percent even after six losses (Poland B 1977).

Recurrent abortion involves more than 500,000 women in the United States per year (Bick 2000). Within the past ten years interest in correlations between thrombophilia and complications of pregnancy has remarkably increased. Thrombotic processes may also be involved in other serious obstetric complications, such as pre-eclampsia, intrauterine growth retardation and placental abruption by impairment of placental perfusion. Pregnancy itself induces a physiological hyper-coagulation state (Bick 2000) (Clark P 1998) (Stirling Y 1984) that might be aggravated by inherited or acquired thrombophilia. Results of studies on pregnancy complications in women with thrombophilia have been conflicting. This heterogeneous group of disorders results in increased venous and arterial thrombosis. Some thrombophilic states in RPL may be acquired such as antiphospholipid syndrome (APS) or heritable.

\subsubsection{Acquired thrombophilia}

Several studies have reported the presence of various autoantibodies in patients with RPL (Roussev RG 1996). However, only the antiphospholipid antibodies (APL) have been clearly associated to recurrent pregnancy losses both in patients with a known autoimmune disease, as APS or systemic lupus erythematous (SLE), and in the general population.

APL were thought to be directed against negatively charged phospholipids, but it has been shown that they are often directed against a protein cofactor, called beta 2 glycoprotein 1 , that assists antibody association with the phospholipid (McNeil HP 1990). APL has been associated with thrombotic complications: some are systemic and some are pregnancy specific-spontaneous abortion, stillbirth, intrauterine growth retardation, and preeclampsia (Harris 1986). Diagnosis of this syndrome requires at least one of each clinical and laboratory criterion 
(ACOG 2005). Clinical criteria are: one or more confirmed episode of vascular thrombosis of any type (venous, arterial, small vessel) and/or pregnancy complications (three or more consecutive spontaneous pregnancy losses at less than 10 weeks of

gestation, one or more fetal deaths at greater than 10 weeks of gestation, one or more preterm births at less than 34 weeks of gestation secondary to severe

preeclampsia or placental insufficiency). Laboratory criteria are: positive plasma levels of anticardiolipin antibodies of the IgG or IgM isotope at medium to high levels and/or positive plasma levels of lupus anticoagulant. Testing must be positive on two or more occasions, 12 weeks or more apart (Miyakis S 2006).

The APS is the autoimmune disease most commonly associated with RPL (Rai RS 1995) to as low as 15\% (Empson M 2002) and the presence of antiphospholipid antibodies is a major risk factor for an adverse pregnancy outcome (Out HJ 1992).

There is still controversy over the timing (early or late) of pregnancy loss more closely related with aPL. A retrospective study in a group of 366 women with recurrent pregnancy losses compared the type of prior pregnancy loss between women with and without APL (Oshiro et al, 1996). A total of 79 women included in the study tested positive for APL, while 290 did not. The rate of prior early pregnancy loss was similar in both groups $(>80 \%)$. However, those patients with APL had $50 \%$ of prior late pregnancy losses compared with $<25 \%$ late pregnancy loss rate in women without APL. The specificity of late pregnancy loss for the presence of APL was $76 \%$ compared with only $6 \%$ for two or more early pregnancy losses, thus suggesting that late pregnancy loss is the most frequent type of loss associated with APS. Other studies have found that most of the APL-related pregnancy losses were biochemical pregnancy losses or early pregnancy losses in nature (Parazzini F 1991) (MacLean MA 1994) (Yetman DL 1996). Experimental data using APS animal models further support the evidence that any type of pregnancy loss (including preimplantation embryos), but mainly embryo reabsorption, may be associated with APL (Ziporen L 1998).

The association of APL with recurrent pregnancy losses in patients with SLE and the APS suggests a causative role but, by no means, it does prove it. The major pregnancy-related target for APL is the placenta and utero-placental insufficiency is often attributed to vasculopathy of the terminal spiral arteries that nourish the placenta intervillous space. These vessels had smaller diameter and showed intimal lawyer thickening, fibrinoid necrosis, and intraluminal thrombosis (De Wolf et al, 1982). In other cases, the infarcted region may show villous congestion and hemorrhage and early trophoblastic necrosis (Bendon RW 1987). In addition to placental infarction and thrombosis, perivillous fibrin deposition and evidence of decidua vascular atherosis, indicative of spiral artery vasculopathy, are seen in some APS cases (Gharavi AE 2001).

The mechanisms by which aPL cause the above described changes are not completely understood and several hypotheses have been proposed. The earliest one is eicosanoid balance alteration mediated by aPL. Inhibition of endothelial cell production of PGI2 (a potent inhibitor of platelet aggregation and vasodilator) and enhancement of placental TXA2 production by plasma from aPL-positive women have been demonstrated by some investigators (Carreras LO 1981) (Schorer AE 1992). Another possible mechanism for thrombosis in APS is the cross- 
reactivity between APL and glycosaminoglycans, a family of heparin-like substances related with the non-thrombotic properties of the vascular endothelium. The inhibition of this function by APL may in part explain the thrombosis associated with them (Chamley LW 1993). Additionally, APL may interfere with the function of natural inhibitors of coagulation such as placental anticoagulant proteins (PAP) and others. PAP is a group of four calcium-dependent phospholipid-binding proteins that inhibit phospholipid- dependent steps of coagulation by making phospholipid inaccessible to clothing factors (Walker JH 1992). The major component of the PAP family is the PAP-1, also called annexin V, which is most abundant in the placenta. Annexin V and aPL compete for phospholipids in coagulation assays (Sammaritano LR 1992). It has been shown that distribution of annexin V over the intervillous surface was significantly lower in patients with APS that in women with recurrent pregnancy losses (Rand JH 1994). These findings suggest that reduced annexin $\mathrm{V}$ production and inhibition of its anticoagulant function by aPL may play a role in pregnancy loss in APS patients.

However, other non-thrombotic mechanisms have been implicated, being interference with the embryonic implantation the one that has received more attention. The APL have been found to react directly with third trimester villous trophoblastic cells (Lyden TW 1992) (Di Simone N 2000), prevent proliferation of trophoblast derived from choriocarcinoma cells (Chamley LW 1993), inhibit in vitro chemotaxis and differentiation of villous trophoblast isolated from third trimester placentae (Di Simone N 2000), decrease trophoblast invasion (Sebire NJ 2002) (Bose P 2005), and inhibit extra-villous trophoblast differentiation (Quenby $S$ 2005). Furthermore, APL can induce pregnancy loss in mice by impairing the embryonic implantation capacity, likely because a direct interaction with the throphoectoderm cells (Sthoeger ZM 1993).

Additionally, aPL may impair the placenta production of chorionic gonadotropin during the early phases of pregnancy, thus determining the embryonic evolution (Shurtz-Swirski $R$ 1993) and, in the mice model, APS is associated with a diminished secretion of interleukin-3, positively related with pregnancy the pregnancy loss is prevented by in vitro administration of recombinant interleukin-3 (Fishman P 1993).

Furthermore, the role of complement activation by the aPL has also received a great deal of attention. Several studies have suggested that activation of the complement cascade is necessary for aPL-mediated thrombophilia and fetal loss (G. G.-O. Pierangeli SS n.d.) (Holers VM 2002). It was found that inhibition of the complement cascade in vivo, using the $C 3$ convertase inhibitor complement receptor 1-related gene protein y (Crry)-Ig, blocks aPLinduced fetal loss and growth retardation, and reversed aPL-mediated thrombosis (Holers VM 2002).

\subsubsection{Inherited thrombophilia}

In 1996 the first reports on an association between other forms of thrombophilia and recurrent pregnancy loss were published (Preston FE 1996) (Rai RS 1995) (Sanson BJ, 1996). Since then numerous case control studies investigating the impact of thrombophilia on pregnancy loss have been conducted (Kupferminc MJ 1999) (Gris JC R.-N. S., 1997) (Grandone E 1997) (Younis JS, 2000) (Pihusch R 2001) (Alonso A, 2002) (Rasmussen A, 2004). In most of these studies factor 
V Leiden (Factor V 1691 G>A), prothrombin 20210 G>A and the methylene tetrahydrofolate gene $677 \mathrm{C}>\mathrm{T}$ variations were determined. Some studies also included other classical markers of thrombophilia, such as antithrombin III, protein C and protein S deficiency and APL (Kupferminc MJ 1999)(Kupferminc MJ, 1999) (Gris JC Q. I., 2000).

The normal coagulation pathway is pivotal for the pregnancy outcomes. Also any kind of disorder in coagulation pathway may cause thrombophilia that may be the reason of placental insufficiency and pregnancy loss (Reznikoff-Etievan MF, 2001). It has become clear that prothrombotic changes are associated with a substantial proportion of these fetal losses. Thrombophilic defects, including mutations in factor V Leiden and prothrombin $20210 \mathrm{G}>\mathrm{A}$, and deficiencies in protein C, protein S, and antithrombin III, have been reported in 49-65\% of women with pregnancy complications and in 18-22\% of women with normal pregnancies (B. 1999) (Kupferminc MJ, 1999).

Therefore, the role of thrombophilias in RPL has generated a great deal of interest. This heterogeneous group of disorders results in increased venous and arterial thrombosis. Although some thrombophilic states in RPL may be acquired such as APS, most are heritable such as hyperhomocyteinemia, activated protein $C$ resistance, deficiencies in proteins $C$ and $\mathrm{S}$, mutations in prothrombin, and mutations in antithrombin III. The three most known common genetic markers for thrombophilia to predispose to venous thrombosis are; factor $\mathrm{V}$ Leiden (FVL), methylenetetrahydrofolate reductase mutation (MTHFR $677 \mathrm{C}>\mathrm{T}$ ) and prothrombin gene mutation. Thrombophilic disorders have generated considerable interest in the field of RPL. Thrombophilia is an important predisposition to thrombosis due to a procoagulant state. Several blood-clotting disorders are grouped under the term of thrombophilia. Clinical studies suggest that the underlying pathophysiological mechanism is mediated via hypercoagulation, leading to utero-placental insufficiency with resultant pregnancy loss. The basis for the association between adverse fetal outcomes and heritable thrombophilias has focused on the mechanisms of impaired placental development and function secondary to venous or arterial thrombosis at the maternal-fetal interface (Aubard Y, 2000) (Cotter AM 2001) (Jeanine F, 2010).

Mutation in the gene-encoding factor $\mathrm{V}$ results in a protein that is resistant to the effects of activated protein $\mathrm{C}(\mathrm{aPC})$. The most common of a variety of mutations is at position 506 with a glutamine substitution for arginine; this FV: R506Q mutation is called the factor V Leiden mutation. The mutation results in a protein resistant to the effects of activated protein $\mathrm{C}(\mathrm{aPC})$. The net result is increased the cleavage of prothrombin to thrombin, which causes excessive coagulation.

The resistance to aPC has emerged as the commonest genetic cause of thromboembolism. It is caused by FVL in $95 \%$ of cases. The risk of thrombosis is increased 5- to 10-fold in heterozygous carriers of FVL, and 100-fold in homozygosis (Kovalevsky G, 2004).

Inherited decreased or absent antithrombin III activity will lead to increased thrombin formation and clotting. Prothrombin gene mutation is signaled by a defect in clotting factor II at position G20210A. The relative risk for thrombosis in patients with this mutation is two-fold in heterozygotes. 
Individuals with hiperhomocisteinemia exhibit a deficiency of folate due to the presence of the methylene tetrahydrofolate reductase mutation (MTHRF $677 \mathrm{C}>\mathrm{T}$ C677 T). The thrombotic risk is increased two-fold in homozygosis; and in the heterozygous state for Antithrombin III deficiency, the risk is 20 - to 50 -fold.

Consistent with general thrombotic risk, carriage of combinations of two or more inherited thrombophilic defects has particularly strong association with adverse pregnancy outcomes (Lockwood C. J., 2002) (Preston FE, 1996). Considerable attention has been directed recently toward a possible relationship between thrombophilias and certain pregnancy complications other than venous thrombosis (De Santis M, 2006).

\subsubsection{In vitro fertilization failures and thrombophilia}

The known or purported causality of phospholipid antibodies and coagulation factors on recurrent pregnancy loss long ago spilled over into the arena of conception with IVF or more precisely, the lack of it. Some have argued that without implantation to signal the arrival of an embryo, it would be improbable for serum or tissue-based response elements to prevent implantation. Others have argued that the effect is unrelated to the embryo, but rather the negative impact is at the level of the endometrium. The Practice Committee of the American Society for Reproductive Medicine released a Committee Opinion in 1999, which it reviewed again in 2008, "Anti-phospholipid antibodies (APA) do not affect IVF success" (Practice Committee of American Society for Reproductive Medicine. 2012). The review culled 16 peer-reviewed papers, of which 7 included appropriate endpoints and controls. There was no statistically significant impact of the presence of phospholipid antibodies on IVF outcomes neither when studies were examined individually nor when the data were aggregated in the 2,053 patients studied. The authors concluded that "assessment of APA is not indicated among couples undergoing IVF. Therapy is not justified on the basis of existing data."

A review was recently published on the topic of thrombophilias and IVF outcome (Di Nisio M, 2011). The authors' initial search yielded 694 studies. Case reports, editorials, reviews, metaanalyses, studies with inadequate outcomes, absence of thrombophilia/anti-phospholipid antibodies, and more than one of the above was excluded and 33 (6,092 patients) were ultimately analyzed. They report that twenty-nine studies (5,270 patients) assessed antiphospholipid antibodies in women treated with assisted reproductive techniques (ART). The prevalence of antibodies in infertile patients varied from $0 \%-45 \%$. When examining casecontrol studies, the authors write "overall, the presence of one or more anti-phospholipid antibodies was associated with a 3-fold higher risk of ART failure." There was a significant degree of heterogeneity across these case-control studies.

\subsection{Thrombophilia and fetal growth restriction}

Obstetricians have been very interested on the possible consequences of thrombophilia because in face of an unexpected pregnancy event, such as fetal growth restriction not 
associated to preeclampsia or arterial hypertension, colagenosis as Systemic Lupus or any other maternal identified disease. This has been the casa once many patients that would have the profile for antiphospholipid syndrome showed no abnormal antibodies on their laboratory workup. So, there would be another group of women that would have another type of "coagulation disorder" that would have to be sorted out.

Considering the possibility that fibrin deposition on the maternal surface of the placenta may impair gas exchanges and nutritional elements between mother and fetus, the model of a thrombophilic induced placental insufficiency seems very attractive.

It has to be emphasized that most studies focus on the maternal aspect of maternal thrombosis in thrombophilia and less is regarded on the obstetrical and fetal complications of thrombophilia in pregnancy.

It has been shown by some authors that this association is found in case control study (Monari F, 2012), where all thrombophilias evaluated had a greater incidence within patients with history of fetal death and that Factor II 20210 G>A gene mutation had also a predictive value for previous fetal deaths in this study population.

Others contest this association when placental infarction is evaluated in comparison to abnormal placentation (Franco C 2011). In this study, no association was found between the presence of thrombophilia and histological findings of infarction.

One of us (R.B., personal communication not published) have observed instances where patients develop placental ultrasonography abnormal image - Grade II or III during second trimester - (Grannum PA, 1979) together with fetal growth restriction that demonstrated true catch up in fetal growth and sustained or regression in placental grade upon prophylactic lowdose heparin and aspirin regimen. In two occasions patients showed to be Leiden Factor heterozygous and Protein S deficiency.

One interesting study showed an increase in the frequency of patients with prothrombin gene mutation associated to IUGR and abruptio placentae (Kupferminc MJ, Peri H, Zwang E, Yaron Y, Wolman I, 2000).

Although randomized trial are still necessary to address the question whether treatment should be advised for women with diagnosed hereditary thrombophilia to prevent adverse pregnancy results, many authors agree that treatment ensures good results, like the one reported by results Kosar (Kosar A 2011). The live birth rate for treated patients was only $62 \%$, even with treatment, which brings up de the consideration that this is really a high-risk obstetrical population.

One group showed that the institution of low-molecular-weight heparin to women with previous fetal growth restriction or pre eclampsia had a dramatic reduction on the recurrence of these events on subsequent pregnancies (Kupferminc, 2011).

When reviewing the literature one must be careful with the conclusions offered because most of the studies do not have a good enough large sample size to draw final conclusions. 
This is the case of the Australian study comparing pregnancy results of women with and without inherited thrombophilia and positive pregnancy with pre eclampsia, fetal restriction, fetal death or placental abruption. Groups comprised 115 women on each arm and no difference on the frequency of thrombophilia in the group with and without adverse history. Now we have to wonder that for instance, Leiden Factor $\mathrm{V}$ is expected in less than $2 \%$ of any Caucasian population and $20210 \mathrm{G}>\mathrm{A}$ prothrombin gene mutation is even less frequent. A case control study would have to add up at least 600 hundred woman on each arm to be able to draw final conclusions.

A large cohort study of nulliparous women as performed where the results of inherited thrombophilia was blind to caring physicians and only a strong association of $20210 \mathrm{G}>\mathrm{A}$ prothrombin gene mutation was found to adverse results of their pregnancies (pre eclampsia, fetal death, fetal restriction, placenta abruption). None of the other thrombophilia showed association to any of these events in this asymptomatic population (Said, 2010).

When we look in the literature on acquired thrombophilia and fetal growth restriction, there is greater agreement that there is a relation between them.

\subsection{Thrombophilia and preeclampsia}

Preeclampsia is a leading cause of maternal-fetal morbidity and mortality. It accounts for a significant fraction of maternal deaths in developed and underdeveloped countries. Preeclampsia is one of the most researched diseases in medicine, and so far several aspects of its pathophysiology have been elucidated. However, a major concept that prevails among the most important studies is that preeclampsia is a multifactorial disease.

One of the most controversial aspects is the role of acquired and inherited thrombophilia in the development of preeclampsia. In this chapter, we present a review on the studies about thrombophilia and preeclampsia, with a critical standing point and future perspectives on this issue.

How thrombophilia might act as cause or contributor in preeclampsia? Thrombophilias may act as co-factor in decreasing placental function through vascular thrombosis and also may regulate inflammatory pathways and increase intravascular coagulation. Alltogether with other contributors these features may trigger endothelial dysfunction and lead to the clinical and laboratorial picture of preeclampsia (Kupferminc., 2003).

\subsubsection{Inherited thrombophilias}

Among inherited thrombophilias, the most studied are factor V Leiden mutation, $20210 \mathrm{G}>\mathrm{A}$ prothrombin mutation, MTHRF $677 \mathrm{C}>\mathrm{T}$, protein $\mathrm{C}$ deficiency, protein $\mathrm{S}$ deficiency and activated protein $\mathrm{C}$ resistance.

There are conflicting results regarding the association between inherited thrombophilias and preeclampsia. This might be due to several factors: small sample sizes, poor methodological quality, retrospective nature of most studies and heterogeneity in the prevalence of thrombophilia in different populations. 
Initial reports showed a marked increase in the prevalence of thrombophilic mutations in women with preeclampsia compared to women with uneventful pregnancies, with figures of $40 \%$ to $72 \%$ for at least one mutation (Stella CL, 2006) (Kupferminc MJ, 1999). These studies were in most part case-control and included women with late and early-onset, mild and severe preeclampsia, as also HELLP syndrome and eclampsia.

Despite these convincing evidences, several studies further did not confirm such a strong association (Rodger, 2007).

Kosmas et al (Kosmas, 2003) reported a meta-analysis of more than 5,000 women among 19 studies. For the studies published until 2000, an association was found between factor V Leiden and preeclampsia, however, for the studies published in 2001-2002 this association was not confirmed.

Dizon-Towson et al (Dizon-Townson D, 2005) also found no association between factor V Leiden and prothrombin mutations with preeclampsia, and this was a multi-center, prospective study.

Another prospective study (Said, 2010) involving 2034 women did not find significant associations between any inherited thrombophilia and preeclampsia and the authors concluded that the majority of women with inherited thrombophilia have normal pregnancy outcomes.

Alfirevic et al. (Alfirevic, 2002) reported the first systematic review of the association between maternal thrombophilia and preeclampsia, and factor V Leiden mutation (heterozygous), 20210 G>A prothrombin mutation (heterozygous), MTHFR 677C > T (homozygous), protein C deficiency, protein $S$ deficiency and activated protein $C$ resistance were more prevalent among women with preeclampsia.

In a systematic review performed by Robertson et al. (Robertson L, 2006), the odds ratios for several genetic mutations (factor V Leiden, prothrombin mutation, MTHFR 677C $>\mathrm{T}$ and protein S) ranged from 1.37 to 3.49 , with evidence of heterogeneity among some studies.

In a systematic review and meta-analysis, Rodger et al. (Rodger MA, 2010) failed to show a significant association between factor V Leiden and prothrombin gene mutation. This review included ten prospective cohort studies and more than twenty thousand patients.

Combined thrombophilias (being carrier of more than one mutation) might have a stronger association with early-onset, severe preeclampsia and HELLP syndrome, however conclusive and solid evidence is also lacking.

The American College of Obstetricians and Gynecologists (Lockwood C, Wendel G; Committee on Practice Bulletins - Obstetrics., 2011) stated that the evidence is insufficient to conclude that inherited thrombophilia increases the occurrence of preeclampsia and therefore do not recommend screening and treatment for thrombophilia in women with previous preeclampsia.

Lockwood (Lockwood C., 2010) also cautioned against screening and treatment for inherited thrombophilias, unless in the setting of a clinical trial. The author argues that methodological 
quality of the positive associations is questionable, that these associations are modest (3-fold increase) and that large prospective cohort studies did not show a consistent association.

In summary, the most recent evidence points to a weak association between preeclampsia and inherited thrombophilias. Even this evidence derives from small studies, with possible selection and report biases. The recent evidence also discourages treatment with heparin based on a diagnosis of inherited thrombophilia.

\subsubsection{Acquired thrombophilia}

Antiphospholipid antibodies are more frequently encountered in patients with preeclampsia, and in this setting they might be a modulator of the severity of the disease rather than a direct cause.

The Sydney Consensus Statement on Investigational Classification Criteria for the Antiphospholipid Syndrome (Miyakis S, 2006) included eclampsia or severe preeclampsia leading to preterm delivery prior to the 34 th week as clinical criteria. To establish the diagnosis of antiphospholipid syndrome (APS) a laboratory criteria must also be present, which might be detection in the plasma of lupus anticoagulant, or anticardiolipin antibodies (IgG or IgM) or anti-beta2-glycoprotein (IgG or IgM), in at least two occasions, 12 weeks apart, and according to specific standard laboratory guidelines.

Do Prado et al (do Prado AD, 2010) performed a systematic review on the association between preeclampsia and anticardiolipin antibodies. The authors found a significant association with an odds ratio of 11.15 for severe preeclampsia and 2.86 for preeclampsia.

Abou-Nassar et al. (Abou-Nassar K, 2011) Published a systematic review of antiphospholipid antibodies and preeclampsia and found an inconsistent association, detected only in casecontrol studies but not in cohort studies, and of lower magnitude.

Although controversial, recent evidence suggests that treatment with heparin and low-dose aspirin in order to reduce recurrence risk is warranted in this situation, with overall pregnancy success rates of more than 70\% (Ernest JM, 2011) (Lockwood C., 2010).

It must also be noted that women with APS are at greater risk of thromboembolism, and anticoagulation should be prescribed for this purpose also.

\section{Author details}

Ricardo Barini, Joyce Annichino-Bizzache, Egle Couto, Marcelo Luis Nomura, Adriana Goes Soligo and Isabela Nelly Machado

Faculdade de Ciências Médicas UNICAMP, SP, Brazil 


\section{References}

[1] Abou-Nassar K, Carrier M, Ramsay T, Rodger MA. "The association between antiphospholipid antibodies and placenta mediated complications: a systematic review and meta-analysis." Thromb Res 128, no. 1 (Jul 2011): 77-85.

[2] ACOG. "Antiphospholipid syndrome." Practice Bulletin No. 68, Nov 2005.

[3] Alfirevic, Z., Roberts, D., Martlew, V. "How strong is the association between maternal thrombophilia and adverse pregnancy outcome? A systematic review." Eur J Obstet Gynecol Reprod Biol, Feb 2002: 6-14.

[4] Alonso A, Soto I, Urgelles MF, Corte JR, Rodriguez MJ, Pinto CR. "Acquired and inherited thrombophilia in women with unexplained fetal losses." Am J Obstet Gynecol, 2002: 1337 - 42.

[5] Aubard Y, et al. "Hyperhomocysteinema and pregnancy review of our present understanding and therapeutic implications." Eur J Obstet Gynecol, 2000: 157-65.

[6] B., Brenner. "Inherited thrombophilia and pregnancy loss." Thromb Haemost, 1999: 634-640.

[7] Bates SM, Greer IA, Middeldorp S, Veenstra DL, Prabulos AM, Vandvik PO, and American College of Chest Physicians. "VTE, thrombophilia, antithrombotic therapy, and pregnancy: Antithrombotic Therapy and Prevention of Thrombosis, 9th ed: American College of Chest Physicians Evidence-Based Clinical Practice Guidelines." Chest. 141, no. 2 Suppl (Feb 2012): e691S-736S.

[8] Bendon RW, Wilson J, Getahun B, van der Bel-Kahn J. "A maternal death due to thrombotic disease associated with anticardiolipin antibody." Arch Pathol Lab, 1987: 370-372.

[9] Bennet SA, Bagot CN, Arya R. "Pregnancy loss and thrombophilia: the elusive link." Br J Haematol 157 (2012): 529-42.

[10] Bezemer ID, van der Meer FJ, Eikenboom JC, Rosendaal FR, Doggen CJ. "The value of family history as a risk indicator for venous thrombosis." Arch Intern Med 169 (2009): 610 - 615.

[11] Bick, R L. "Recurrent miscarriage syndrome due to blood coagulation protein/platelet defects: prevalence, treatment and outcome results. DRW Metroplex Recurrent Miscarriage Syndrome Cooperative Group." Clin Appl Thromb Hemost 6 (2000): 115-25.

[12] Biron-Andreani C, Schved JF, Daures JP. "Factor V Leiden mutation and pregnancyrelated venous thromboembolism:what is the exact risk? Results from a meta-analysis." Thromb Haemost 18, no. 96 (2006): 14-18.

[13] Boklage, CE. "Survival probability of human conceptions from fertilization to term." Int J Fertil 35, no. 2 (Mar-Apr 1990): 75, 79-80, 81-94. 
[14] Bose P, Black S, Kadyrov $\mathrm{M}$ et al. "Heparin and aspirin attenuate placental apoptosis in vitro: implications for early pregnancy failure." Am J Obstet Gynecol, 2005: 23-30.

[15] Brown DW, Dueker N, Jamieson DJ, Cole JW, Wozniak MA, Stern BJ, Giles WH, Kittner SJ. "Preeclampsia and the risk of ischemic stroke among young women: results from the Stroke Prevention in Young Women Study." Stroke 37, no. 4 (Apr 2006): 1055-9.

[16] Buchholz T, Thaler CJ. "Inherited Thrombophilia: Impact in Human Reproduction." Am J Reprod Immunol 50 (2003): 20-32.

[17] Bushnell CD, Goldstein LB. "Diagnostic testing for coagulopathies in patients with ischemic stroke." Stroke 31, no. 12 (2000): 3067-78.

[18] Carod-Artal FJ, Nunes SV, Portugal D, Silva TV, Vargas AP. "Ischemic stroke subtypes and thrombophilia in young and elderly Brazilian stroke patients admitted to a rehabilitation hospital." Stroke 36, no. 9 (2005): 2012-4.

[19] Carreras LO, Defreyn G, Machin SJ et al. "Arterial thrombosis, intrauterine death and "lupus" antiocoagulant: detec- tion of immunoglobulin interfering with prostacyclin formation." Lancet, 1981: 244-246.

[20] Chamley LW, McKay EJ, Pattison NS. "Inhibition of heparin/antithrombin III cofactor activity by anticardiolipin anti-bodies: a mechanism for thrombosis." Thromb Res, 1993: 103-11.

[21] Clark P, Brennand J, Conkie JA, McCall F, Greer IA, Walker ID. "Activated protein C sensitivity, protein $C$, protein $S$ and coagulation in normal pregnancy.." Thromb Haemost 79 ( 1998): 1166 - 70.

[22] Conard J, Horellou MH, Van Dreden P, Lecompte T, Samama M. "Thrombosis and pregnancy in congenital deficiencies in AT III, protein C or protein S: study of 78 women." Thromb Haemost 63 (1990): 319 - 320.

[23] Coppens M, Folkeringa N, Teune M, et al. "Natural course of the subsequent pregnancy after a single loss in women with and without the factor $\mathrm{V}$ Leiden or prothrombin 20210A mutations." J Thromb Haemost 5 (2007 ): 1444-1448.

[24] Coppens M, van de Poel MH, Bank I, et al. "A prospective cohort study on the absolute incidence of venous thromboembolism and arterial cardiovascular disease in asymptomatic carriers of the prothrombin 20210A mutation." Blood 108 (2006): 2604 2607.

[25] Cordoba I, Pegenaute C, González-López TJ, Chillon C, Sarasquete ME, Martin-Herrero F, Guerrero C, Cabrero M, Garcia Sanchez MH, Pabon P, Lozano FS, Gonzalez M, Alberca I, González-Porras JR). "Risk of placenta-mediated pregnancy complications or pregnancy-related VTE in VTE-asymptomatic families of probands with VTE and heterozygosity for factor V Leiden or G20210 prothrombin mutation." Eur J Haematol 8, no. 3 (Sep 2012): 250-5. 
[26] Cotter AM, et al. "Elevated plasma homocysteine in early pregnancy: A risk factor for the development of severe preeclampsia." Am J Obstet Gynecol, 2001: 781-5.

[27] Couto E, Nomura ML, Barini R, Silva JL. "Pregnancy- associated venous thromboembolism in combined heterozygous factor V Leiden and prothrombin G2022110A mutations." São Paulo Med J. 123 (2005): 286-88.

[28] De Santis M, et al. "Inherited and acquired thrombophilia: Pregnancy outcome and treatment." Reprod Toxicol, 2006: 227.

[29] Di Nisio M, Rutjes AWS, Ferrante N, Tiboni GM, Cuccurullo F, Porreca E. "Thrombophilia and outcomes of assisted reproduction technologies: a sys- tematic review and meta-analysis." Blood, 2011: 2670-8.

[30] Di Simone N, Meroni PL, Del Papa N et al. " Antiphospholipid antibodies affect trophoblast gonadotrophin secretion through adhered beta-2-glycoportein I." Arthritis Rheum, 2000: 140-50.

[31] D’Amico, EA. Trombofilia. Edited by Lorenzi TF. Rio de Janeiro, RJ: Guanabara Koogan;, 2006.

[32] Dizon-Townson D, Miller C, Sibai B, et al. "The relationship of the Factor V Leiden mutation in pregnancy outcomes for mother and fetus." Obstet Gynecol 106 (2005): 517-24.

[33] do Prado AD, Piovesan DM, Staub HL, Horta BL. "Association of anticardiolipin antibodies with preeclampsia: a systematic review and meta-analysis." Obstet Gynecol 116, no. 6 (Dec 2010): 1433-43.

[34] Empson M, Lassere M, Craig JC, Scott J. "Recurrent pregnancy loss with antiphospholipid antibody: a systematic review of therapeutic trials." Obstet Gynecol, 2002: 135-144.

[35] Ernest JM, Marshburn PB, Kutteh WH. "Obstetric antiphospholipid syndrome: an update on pathophysiology and management." Semin Reprod Med. 29, no. 6 (Nov 2011): 522-39.

[36] Fischer-Betz R, Specker C, Brinks R, Schneider M. "Pregnancy outcome in patients with antiphospholipid syndrome after cerebral ischaemic events: an observational study." Lupus 21, no. 11 (2012): 1183-9.

[37] Fishman P, Falach-Vaknine E, Zigelman R et al. "Prevention of fetal loss in experimental anti-phospholipid syndrome by in vitro administration of recombinant interleukin-3." J Clin Invest, 1993: 1834-77.

[38] Fogerty AE, Connors JM. "Management of inherited thrombophilia in pregnancy." Curr Opin Endocrinol Diabetes Obes 16 (2009): 464-9.

[39] Franco C, Walker M, Robertson J, Fitzgerald B, Keating S, McLeod A, Kingdom JC. "Placental infarction and thrombophilia." Obstet Gynecol, Apr 2011: 929-34. 
[40] Friederich PW, Sanson BJ, Simioni P, et al. "Frequency of pregnancy-related venous thromboembolism in anticoagulant factor-deficient women: implications for prophylaxis." Ann Intern Med 125 (1996): 955 - 960.

[41] Gharavi AE, Pierangeli SS, Harris EN. "Mechanisms of pregnancy loss in antiphospholipid syndrome." Clin Obstet Gynecol, 2001: 11-19.

[42] Grandone E, Margaglione M, Colaizzo D, et al. "Factor V Leiden is associated with repeated and recurrent unexplained fetal losses." Thromb Haemost, 1997: 822 - 4.

[43] Grannum PA, Berkowitz RL, Hobbins JC. "The ultrasonic changes in the maturing placenta and their relation to fetal pulmonic maturity." Am J Obstet Gynecol 133, no. 8 (Apr 1979): 915-22.

[44] Gris JC, Quere I, Sanmarco M, et al. "Antiphospholipid and antiprotein syndromes in non-thrombotic, non- autoimmune women with unexplained recurrent primary early foetal loss. The Nimes Obstetricians and Haematologists Study NOHA." Thromb Haemost, 2000: 228 - 36.

[45] Gris JC, Ripart-Neveu S, Maugard C, et al. "Respective evaluation of the prevalence of haemostasis abnormalities in unexplained primary early recurrent miscarriages. The Nimes Obstetricians and Haematologists (NOHA) Study." Thromb Haemost, 1997: 1096 - 103.

[46] Haeusler KG, Herm J, Hoppe B, Kasabov R, Malzahn U, Endres M, Koscielny J, Jungehulsing GJ. "Thrombophilia screening in young patients with cryptogenic stroke. Prevalence of gene polymorphisms compared to healthy blood donors and impact on secondary stroke prevention." Hamostaseologie 32, no. 2 (2012): 147-52.

[47] Hamzi K, Tazzite A, Nadifi S. "Large-scale meta-analysis of genetic studies in ischemic stroke: Five genes involving 152,797 individuals." Indian J Hum Genet 17, no. 3 (2011): 212-7.

[48] Hankey GJ, Eikelboom JW, van Bockxmeer FM, Lofthouse E, Staples N, Baker RI. "Inherited thrombophilia in ischemic stroke and its pathogenic subtypes." Stroke 32, no. 8 (2001): 1793-9.

[49] Harris, EN. "Syndrome of the black swan." Br J Rheumatol 26 (1986): 324-326.

[50] Hatasaka, H H. "Recurrent miscarriage: epidemiologic factors, definitions and incidence." Clin Obstet Gynecol 37 (1994): 325-334.

[51] Heit JA, Kobbervig CE, James AH, Petterson TM, Bailey KR, Melton LJ III. "Trends in the incidence of venous thromboembolism during pregnancy or postpartum: a 30year population based study." Ann Intern Med. 143 (2005): 697-706.

[52] Hoffman E, Hedlund E, Perin T, Lyndrup J. Is thrombophilia a risk factor for placenta - mediated pregnancy complications? Vol. 286. 3 vols. Arch Gynecol Obstet, 2012. 
[53] Hogge, WA. et al. "The clinical use of karyotyping spontaneous abortions." Am. J. Obstet. Gynecol. 189 (2003): 397-400.

[54] Holers VM, Girardi G, Mo L et al. "C3 activation is required for anti-phospholipid antibody-induced fetal loss." J Exp Med, 2002: 211-220.

[55] Jaigobin C, Silver FL. "Stroke and pregnancy." Stroke 31, no. 12 (Dec 2000): 2948-51.

[56] Jeanine F, et al. "Prenatal Screening for Thrombophilias: Indications and Controversies." Clin Lab Med, 2010: 747-760.

[57] Kim RJ, Becker RC. "Association between factor V Leiden, prothrombin G20210A, and methylenetetrahydrofolate reductase C677T mutations and events of the arterial circulatory system: a meta-analysis of published studies." Am Heart J. 146, no. 6 (2003): 948-57.

[58] Kosar A, Kasapoglu B, Kalyoncu S, Turan H, Balcik OS, Gümüs EI. "Treatment of adverse perinatal outcome in inherited thrombophilias: a clinical study." Blood Coagul Fibrinolysis, Jan 2011: 14-8.

[59] Kosmas, IP., Tatsioni, A., Ioannidis, JP. "Association of Leiden mutation in factor V gene with hypertension in pregnancy and pre-eclampsia: a meta-analysis." J Hypertens, Jul 2003: 1221-8.

[60] Kovalevsky G, et al. "Evaluation of the association between hereditary thrombophilias and recurrent pregnancy loss: a meta-analysis." Arch Intern Med, 2004: 558-63.

[61] Kupferminc MJ, Eldor A, Steinman N, et al. "Increased frequency of genetic thrombophilia in women with complications of pregnancy." N Engl J Med, 1999: 9-13.

[62] Kupferminc MJ, Peri H, Zwang E, Yaron Y, Wolman I,. "High prevalence of the prothrombin gene mutation in women with intrauterine growth retardation, abruptio placentae and second trimester loss." Acta Obstet Gynecol Scand, Nov 2000: 963-7.

[63] Kupferminc, MJ. Rimon, E. Many, A. Sharon, M. Lessing, JB, Gamzu, R.. "Low molecular weight heparin treatment during subsequent pregnancies of women with inherited thrombophilia and previous severe pregnancy complications." J Matern Fetal Neonatal Med, Aug 2011: 1042-5.

[64] Kupferminc., MJ. "Thrombophilia and pregnancy." Reprod Biol Endocrinol., Nov 2003: 111.

[65] Lockwood C, Wendel G; Committee on Practice Bulletins - Obstetrics. "Practice Bulletin No. 124: Inherited thrombophilias in pregnancy. American College of Obstetricians and Gynecologists Committee on Practice Bulletins-Obstetrics." Obstet Gynecol, Sept 2011: 730-40.

[66] Lockwood, C J. "Inherited thrombophilias in pregnant patients: detection and treatment paradigm." Obstet Gynecol, 2002: 333-341. 
[67] Lockwood, C J. "Inherited thrombophilias in pregnant patients." Prenat Neonat Med, 2001: 3-14.

[68] Lockwood, C.J. 2010. http://www.modernmedicine.com/modernmedicine/Modern +Medicine+Now/Stop-screening-for-inherited-thrombophilias-in-pat/ArticleStandard/Article/detail/668547 (accessed Sept 17, 2012).

[69] Lyden TW, Vogt E, Ng AK, Johnson PM, Rote NS. "Monoclonal antiphospholipid antibody reactivity against human placental trophoblast." J Reprod Immunol, 1992: 114 .

[70] Machac S, Lubusky M, Prochazka M, Streda R. "Prevalece of inherited thrombophilia in patients with severe ovarian hyperstimulation syndrome." Biomed Pap Med Fac Univ Palacky Olomouc Czech Repub. 150, no. 2 (2006): 289-292.

[71] MacLean MA, Cumming GP, McCall F, Walker ID, Walker JJ. "The prevalence of lupus anticoagulant and anticardiolipin antibodies in women with a history of first trimester miscarriages." Br J Obstet Gynaecol, 1994: 103-106.

[72] Marik PE, Plante LA. "Venous thromboembolic disease and pregnancy." N Engl J Med. 359 (2008): 2025-33.

[73] Martinelli I, Battaglioli T, De Stefano V, et al. "GIT (Gruppo Italiano Trombofilia). The risk of fi rst venous Tromboembolism during pregnancy and puerperium in double heterozygotes for factor V Leiden and prothrombin G20210A." J Thromb Haemost 6 (2008): 494 - 498.

[74] McColl MD, Ramsay JE, Tait RC, Walker ID, McCall F, Conkie JA, et al. "Risk factors for pregnancy associated venous thromboembolism." Thromb Haemost. 78 (1997): 1183-8.

[75] McNeil HP, et al. "Anti-phospholipid antibodies are directed against a complex antigen that includes a lipid binding inhibitor of coagulation: beta 2-glycoprotein I (apolipoprotein H).." Proc Natl Acad Sci U S A 87 (1990): 4120-4124.

[76] Miyakis S, Lockshin MD, Atsumi T, Branch DW, Brey RL, Cervera R, Derksen RH, DE Groot PG, Koike T, Meroni PL, Reber G, Shoenfeld Y, Tincani A, Vlachoyiannopoulos PG, Krilis SA. "International consensus statement on an update of the classification criteria for definite antiphospholipid syndrome (APS)." J Thromb Haemost 4, no. 2 (2006): 295-306.

[77] Miyata T, Sato Y, Ishikawa J, Okada H, Takeshita S, Sakata T, et al. "Prevalence of genetic mutations in protein $S$, protein $C$ and antithrombin genes in Japanese patients with deep vein thrombosis." Thromb Res. 124 (2009): 14-8.

[78] Monari F, Alberico S, Avagliano L, Cetin I, Cozzolino S, Gargano G, Marozio L, Mecacci F, Neri I, Tranquilli AL, Venturini P, Facchinetti F. "Relation between maternal thrombophilia and stillbirth according to causes/associated conditions of death." Early Hum Dev., Apr 2012: 251-4. 
[79] Moreira, C.E.S.1, M.A.S.1 Ogino, A.C.R.2 de Moraes, and T.J.C. Neiva. "Hemostasia na gravidez estudo prospectivo RBAC." RBAC 42, no. 2 (2008): 111-113.

[80] Nomura ML, Olivares C, Min L L. "Stoke in pregnacy and puerperium: a Brazilian case series." Personal data, unpublished. 2012.

[81] Oshiro BT, Silver RM, Scott JR, Yu H, Branch DW. "Antiphospholipid antibodies and fetal death." Obstet Gynecol, 1996: 489-493.

[82] Out HJ, et al. " A prospective, controlled multicenter study of the obstetric risks of pregnant women with antiphospholipid antibodies." Br J Obstet Gynaecol, 1992: 2632 .

[83] Parazzini F, Acaia B, Faden D, Lovotti M, Marelli G, Cortelazzo S. "Antiphospholipid antibodies and recurrent abortion." Obstet Gynecol, Jun 1991: 854-8.

[84] Pierangeli SS, Girardi G, Vega-Ostertag M, Liu X, Espinola RG, Salmon J. "Requirement of activation of complement C3 and C5 for antiphospholipid antibody-mediated thrombophilia." Arthritis Rheum., Jul 2005: 2120-4.

[85] Pierangeli SS, Girardi G, Vega-Ostertag ME, Liu X, Espinola RG, Salmon J. "Requirement of activation of complement C3 and C5 for antiphospholipid antibody-mediated thrombophilia." Arthritis Rheum, 2120-2124.

[86] Pierangeli SS, Leader B, Barilaro G, Willis R, Branch DW. Acquired and inherited thrombophilic disorders in pregnancy. Vol. 38. Obstet Gynecol Clin N Am, 2011.

[87] Pihusch R, Buchholz T, Lohse P, et al. "Thrombophilic gene mutations and recurrent spontaneous abortion: prothrombin mutation increases the risk in the first trimester." Am J Reprod Immunol, 2001: 124 - 31.

[88] Poland B, et al. "Reproductive counseling in patients who have had a spontaneous abortion." Am J Obstet Gynecol, 1977: 127: 685.

[89] Pomp ER, Lenselink AM, Rosendaal FR, Doggen CJ. "Pregnancy, the postpartum period and prothrombotic defects: risk of venous thrombosis in the MEGA study." J Thromb Haemost. 6 (2008): 632-7.

[90] Practice Committee of American Society for Reproductive Medicine. "Diagnostic evaluation of the infertile female: a committee opinion." Fertil Steril, Aug 2012: 302-7.

[91] Preston FE, Rosendaal FR, Walker ID, et al. "Increased fetal loss in women with heritable thrombophilia." Lancet, 1996: 913-6.

[92] Quenby S, Mountfield S, Cartwright JE, Whitley GS, Chamley L, Vince G. "Antiphospholipid antibodies precent extravillous trophoblast differentiation.." Fertil Steril, 2005: 691-8. 
[93] Rai RS, Clifford K, Cohen H, Regan L. "High prospective fetal loss rate in untreated pregnancies of women with recurrent miscarriage and antiphospholipid antibodies." Hum Reprod, 1995: 3301-3304.

[94] Rand JH, Wu XX, Guller S et al. "Reduction of annexin-V (placental anticoagulant protein-I) on placental villi of women with antiphospholipid antibodies and recurrent spontaneous abortion." Am J Obstet Gynecol, 1994: 1566-72.

[95] Rasmussen A, Ravn P. "High frequency of congenital thrombophilia in women with pathological pregnancies?" Acta Obstet Gynecol Scand, 2004: 808 - 17.

[96] Regan, L. et al. "Influence of past reproductive performance on risk of spontaneous abortion." BMJ 299 (1989): 541-545.

[97] Reistma PH, Rosendaal FR. "Past and future of genetic research in thrombosis." J Thromb Haemost 5 (2007): 264-9.

[98] Ren A, Wang J. "Methylenehydrofolate reductase C677T polymorphism and the risk of unexplained recurrent pregnancy loss: a meta-analysis." Fertility and Sterility 86 (2006): 1716-22.

[99] Reznikoff-Etievan MF, et al. "Factor V Leiden and G20210A prothrombin mutations are risk factors for very early recurrent miscarriage." BJOG, 2001: 1251 - 1254.

[100] Robertson L, Wu O, Langhorne P, Twaddle S, Clark P, Lowe GD, Walker ID, Greaves M, Brenkel I, Regan L, Greer IA. "Thrombosis: Risk and Economic Assessment of Thrombophilia Screening (TREATS) Study.Thrombophilia in pregnancy: a systematic review." Br J Haematol 132, no. 2 (Jan 2006): 171-96.

[101] Rodger MA, Betancourt MT, Clark P, et al. "The association of factor V Leiden and prothrombin gene mutation and placenta-mediated pregnancy complications: a systematic review and meta-analysis of prospective cohort studies." PLoS Med 7, no. 6 (2010): e1000292.

[102] Rodger, MA., Paidas, M. "Do thrombophilias cause placenta-mediated pregnancy complications?" Semin Thromb Hemost, Sep 2007: 597-603.

[103] Roussev RG, Kaider BD, Price DE, Coulam CB. "Laboratory evaluation of women experiencing reproductive failure." Am J Reprod Immunol 35 (1996): 415-420.

[104] Said JM, Higgins JR, Moses EK, Walker SP, Monagle PT, Brennecke SP. "Inherited thrombophilias and adverse pregnancy outcomes: a case-control study in an Australian population." Acta Obstet Gynecol Scand, Feb 2012: 250-5.

[105] Said, JM., Higgins, JR., Moses, EK., Walker, SP., Borg, AJ., Monagle, PT., Brennecke, SP. "Inherited thrombophilia polymorphisms and pregnancy outcomes in nulliparous women." Obstet Gynecol, Jan 2010: 5-13. 
[106] Sammaritano LR, Gharavi AE, Soberano C, Levy RA, Lockshin MD. "Phospholipid binding of antiphospholipid antibodies and placental anticoagulant protein." J Clin Immunol, 1992: 27-35.

[107] Sanson BJ, Friederich PW, Simioni P, et al. "The risk of abortion and stillbirth in antithrombin-, protein C-, and protein S-deficient women." Thromb Haemost, 1996: 387 -8 .

[108] Schorer AE, Duane PG, Woods VL, Niewoehner DE. "Some antiphospholipid antibodies inhibit phospholipase A2 activity." J Lab Clin Med, 1992: 67-77.

[109] Scott CA, Bewley S, Rudd A, Spark P, Kurinczuk JJ, Brocklehurst P, Knight M. "Incidence, risk factors, management, and outcomes of stroke in pregnancy." Obstet Gynecol 120, no. 2 Pt 1 (2012): 318-24.

[110] Sebire NJ, Fox H, Backos M, Rai R, Paterson C, Regan L. "Defective endovascular trophoblast invasion in primary antiphos- pholipid antibody syndrome-associated early pregnancy failure.." Hum Reprod, 2002: 1067-71.

[111] Shurtz-Swirski R, Inbar O, Blank M et al. "In vitro effect of anticardiolipin autoantibodies upon total and pulsatile placental hCG secretion during early pregnancy.." Am J Reprod Immunol, 1993: 206-10.

[112] Stella CL, How HY, Sibai BM. "Thrombophilia and adverse maternal-perinatal outcome: controversies in screening and management." Am J Perinatol, Nov 2006: 499-506.

[113] Sthoeger ZM, Mozes E, Tartakovsky B. "Anti-cardiolipin antibodies induce pregnancy failure by impairing embryonic implantation.." Proc Natl Acad Sci USA, 1993: 6464-646.

[114] Stirling Y, Woolf L, North WR, Seghatchian MJ, Meade TW. "Haemostasis in normal pregnancy." Thromb Haemost 52 (1984): 176 - 82

[115] Tormene D, Simioni P, Prandoni P, et al. "Factor V Leiden mutation and the risk of venous thromboembolism in pregnant women." Haematologica 86 (2001): 1305 1309 .

[116] Vaquero E, Lazzarin N, Caserta D, Valensise H, Baldi M, Moscarini M, Arduii D. "Diagnostic evaluation of women experiencing repeated in vitro fertilization failure." Eur J Gynecol Reprod Biol 10 (2005): 1253-5.

[117] Voetsch B, Damasceno BP, Camargo EC, Massaro A, Bacheschi LA, Scaff M, Annichino-Bizzacchi JM, Arruda VR. "nherited thrombophilia as a risk factor for the development of ischemic stroke in young adults. I." Thromb Haemost 83, no. 2 (2000): 229-33.

[118] Walker JH, Boustead CM, Koster JJ, Bewley M, Waller DA. "Annexin V, a calciumdependent phospholipid-binding protein.." Biochem Soc Trans, 1992: 828-33. 
[119] Weber R, Busch E. "[Thrombophilias in patients with ischemic stroke. Indication and calculated costs for evidence-based diagnostics and treatment]." Nervenarzt 76, no. 2 (2005): 193-201.

[120] Yetman DL, Kutteh WH. "Antiphospholipid antibody panels and recurrent pregnancy loss: prevalence of anticardiolipin anti- bodies compared with other antiphospholipid antibodies." Fertil Steril, 1996: 540-546.

[121] Younis JS, Brenner B, Ohel G, Tal J, Lanir N, Ben-Ami M. Activated protein C resistance and factor $\mathrm{V}$ Leiden mutation can be associated with first- as well as second- trimester recurrent pregnancy loss. Am J Reprod Immunol, 2000: 31 - 5.

[122] Ziporen L, Shoenfeld Y. "Anti-phospholipid syndrome: from patient's bedside to experimental animal models and back to the patient's bedside." Hematol Cell Ther, 40 1998: 175-182. 